\title{
A Autonomia da Vontade nos Contratos Internacionais do Comércio
}

MARISTELA BASSO

Advogada e Professora de Direito Internacional

SUMÁRIO

1. Consideraçoes Iniciais; 2. A Autonomia da Vontade no Contrato Internacional; 3. A Autonomia da Vontade e a Lei Aplicável ao Contrato: 3.1. A Regra de Direito Internacional Privado que Faculta as Partes a Escolha da Lei plicavel ao Contrato nos Paises do Clil Law; 3.2. O Artigo 9 da Lel de Argra da Aut Arbitral e nas Convençōes Internacionais; 4. O Momento em que Pode Intervir a Liberdade da Escolha das Partes Guanto a Lei Aplicavel ao Contrato e a Questão do Dépeçage; 5. Os Limites Estratégicos à Escolha das Partes Quanto a Lei Aplicável ao Contrato; 6. O Contrato Sem Lei e os Limites da Vontade das Partes; com as Particularidades do Comércio Internacional: 7.1. As Técnicas Alternativas ao Método Conflitual; 7.2. com as Particularidades do Comércio Internacional: 7.1. As Técnicas Alternativas ao Método Conflitual; 7.2. Método Conflitual aos Contratos Internacionais do Comércio; Notas.

\section{CONSIDER AÇÕES INICIAIS}

Não obstante os inúmeros e palpitantes debates travados pelos doutrinadores nacionais ${ }^{1}$ e estrangeiros acerca da autonomia da vontade em direito internacional privado, vale a pena retomar alguns aspectos de uma temática delicatomar alguns aspectos de uma tematica delicada e importante que se refere ao problema do limite da vontade das partes no contrato interção, durante 0 periodo de tratativas, da lei aplicável ao contrato.

No direito contratual o principio da autonomia da vontade se manifesta na liberdade propriamente dita de contratar, de estipular o contrato e seu conteúdo. Significa aquela esfera de liberdade de que gozam as partes, no âmbito do direito privado, de auto-regência de seus próprios interesses, de discutir livremente as condiçoes do contrato pretendido, bem como de esdiçoes do contrato pretendio. bem como de eslavras, é a faculdade das partes de regerem-se lavras, é a faculdade das partes de regerem-se
por suas próprias leis, de praticar um ato juridico determinando-lhe o conteúdo, a forma, as sim como os efeitos.

Simplificadamente, é a aptitlão que possui toda pessoa capaz, pela vontade unilateral ou pelo concurso de vontades, de criar, modificar ou extinguir relaçóes juridicas; vinculada a autonomia da vontade está a teoria normativa do negócio jurídico. Luigi Ferri, a propósito, prefere a expressão "autonomia privada"2, como faculdade de criar, nos limites da lei, normas juridicas $^{3}$.

\section{A AUTONOMIA DA VONTADE NO}

\section{CONTR ATO INTERNACIONAL}

$\mathrm{Na}$ elaboração do contrato internacional, a vontade das partes é amplamente admitida, mas isso não significa uma liberdade de ação ilimitada, um absolutismo, como defendem alguns autores. E verdade que o comércio internacional tem contribuido para fortalecer os alicerces da lex voluntatis, que, entretanto, não pode afastar certos elementos limitadores, tais como: as leis imperativas e de ordem pública que vigoram no pais onde o contrato será executado. Extremamente dificil é a definição de ordem pública e, certamente, não pretendemos abrir aqui esta questão já amplamente debatida. Porém, nos serve a reflexão de que a faculdade de auto-regulamentação dos contraentes, não obstante as teses consensualistas clássicas que defendem a total autonomia contratual das partes, não é ilimitada, e os contraentes não gozam de ampla liberdade na determinação e estipulação da natureza e caracteristicas de suas obrigações. As limitaçōes à liberdade contratual decorrem justamente deste misterioso fenômeno que é a ordem pública, do qual não nos interessa a definição, mas sim a função e o conteúdo

Observa Irineu Strenger que "é tarefa complexa, se não impossivel, identificar e conhecer o exato conteúdo da ordem pública interna internacional, de cada Estado, concernente a contrato". A ordem pública, segundo este autor, "não é determinável por meio de elencos, e nem é possivel adotar métodos analógicos e critérios aproximativos", pois "cada Estado estabelece sua ordem pública, e os tratados internacionais porventura existentes, não têm força jurídica, não ser em virtude da adesão dos Estados"5.

Nos contratos internacionais as limitações autonomia das partes decorrem tanto das nocões de ordem pública interna, como de ordem publica internacional interna a primeira, devepublica internacional. mos entender aquele complexo de normas e principios imperativos determinados pelo legislado e sobre o qual se assenta o edificio juridico, com o entendimento de que cabe basicamente ao julgador a interpretação de seu conteúdo - do foro intimo daquele que julga, alicerçado nos pilares da construção jurídico-social. Vincent Heuzé traz alguns elementos novos à compreensão de or dem pública afirmando que 0 "direito objetivo exerce um estreito controle sobre a utilidade não somente social, mas ainda particular das convençōes, garantindo, paralelamente, sua conformidade à justiça social" 6 .

No que se refere à ordem pública internacional, persiste a questão de em que medida esta pode exercer os mesmos efeitos moduladores de cláusulas livremente estipuladas. Segund Strenger, "na medida em que o direito intern reconhece a sua validade"7.

A questão, portanto, permanece complexa difícil. Assim, os doutrinadores jus-internacionalistas têm procurado reduzir os efeitos da or dem pública e seu impacto sobre o contrato ne gociado. Da mesma forma a jurisprudência tem revelado que os juizes quando devem aplicar leis estrangeiras o fazem com base nas opiniōes le gais de juristas daquele pais, que são os mais habilitados a atestarem o caráter imperativo de suas normas e os seus principios de ordem pública

Devemos ter presente, contudo, que o problema da ordem pública somente se levantará mais tarde, quando o contrato estiver concluido e em fase de execução, pois é neste estágio que pode surgir a questão do direito aplicado ao contrato: se as partes tinham o direito (liberdade) de escolhê-lo e se, escolhendo-o, respeitaram suas regras e principios de ordem pública.

Impõe-se, portanto, no decurso das tratativas, que os negociadores tomem o cuidado de não elaborarem um contrato que pode perder sua eficácia em caso de choque com os principios basilares do edificio jurídico do país onde 0 contrato deva ser executado. Razão pela qual os advogados-negociadores devem conhecer o direito do pais do outro contratante, assim como os sistemas juridicos que direta ou indiretamente geram efeitos sobre o contrato pretendido, segundo os seus elementos de estraneidade.

\section{A AUTONOMIA DA VONTADE E A LEI}

A PLICÁVEL AO CONTRATO

Todo contrato internacional, ainda que sobre ele incidam muitas ordens juridicas distintas, está necessariamente vinculado à lei de um Estado, ainda que alguns doutrinadores defendam a possibilidade de um "contrato sem lei" ou "autoregulamentado".

Existem sistemas juridicos que estabelecem restriçōes ao principio da autonomia contratual, como é o caso do Brasil (art. 9 da Lei de Introdução ao Código Civil brasileiro). Outros limitam a escolha a uma lei que tenha relação com as partes ou com o negócio, por exemplo, a lei do lugar da execução (lex loci execucionis), ou a lei da nacionalidade ou domicílio das partes, oụ a lei da constituição da obrigação (locus regit actum). Outros são totalmente liberais e reconhecem às partes a faculdade de escolha da lei aplicável, que poderá ser 0 direito de um pais considerado neutro, ou aquele que melhor se adapte às circunstancias do contrato, mas evidentemente, esta liberdade sofre certas limitaçōes. 

3.1. A Regra de Direito Internacional
Privado que Faculta as Partes a Escolha da Privado que Faculta as Partes a Escolha da
Lei Aplicável ao Contrato nos Países da "Civil Law"

Partindo da premissa de que todo contrato internacional está necessariamente vinculado à lei de um Estado, devem os negociadores observar que a lei aplicável ao contrato, segundo a var que a lei aplicável ao contrato, segundo a qual este deve fundamentalmente se conformar
frente os seus principios imperativos e de orfrente os seus principios imperativos e de ordem pública, depende da escolha das partes. Então, ainda que o contrato se vincule a muitas ordens juridicas autonomas e independentes (segundo a nacionalidade das partes, domicilio, lugar da constituição da obrigação, etc.) a liberdade das partes encontra como limites "a proibição de violar as regras de ordem pública do sistema juridico com o qual o contrato pode entrar em contado para produzir efeitos"8.

Certamente, ao afirmarmos que a lei aplicável ao contrato depende da escolha das partes. estamos levando em consideração um estudo comparativo entre diversos sistemas nacionais de direito internacional privado, que evidencia uma quase uniformidade no que concerne à le aplicável ao contrato e às obrigaçōes dele resultantes. Esta lei é a lei de autonomia, ou seja, a lei que as partes escolheram para submeter seu contrato; outras regras podem governar cerseu contrato; outra tos aspectos particulares, por exemplo, a regra locus regit actum no que concerne à forma do contrato. Atualmente, a regra de direito inter nacional privado que faculta as partes, de uma maneira ou de outra, escolherem a lei de regência do contrato é encontrada em quase todos os sistemas juridicos nacionais.

A propósito da autonomia da vontade, a controvérsia que se instaurou na doutrina entre a segunda metade do século XIX e inicio deste noss $0^{9}$, parece que hoje perdeu sua força, jus tamente pelo fato de que a regra de autonomia vem consagrada, como já se disse, na imensa maioria dos sistemas de direito internaciona privado do mundo ${ }^{10}$. Na França, já em 1910, a jurisprudência consagrou a regra que confere jurisprudência consagrou a regra que confere as partes a faculdade de escolha da lei aplicável "American Trading Company v. Quebec Steamship Company Limíted", decidiu:
"La loi applicable aux contrats, soit en ce qui concerne leur formation, soit quant à leurs effets et conditions, est celle que les parties ont adoptée"l1.

Recentemente, em 1980, novamente a Corte de Cassação francesa, no caso "Sté Mercator Press", estabeleceu outra célebre fórmula que someda a anterior fixam o direito positivo francês em matéria de contratos internacionais:

"Si la localisation du contrat dépend de la volonté des partie, c'est au juge qu'il appartient, aprés avoir interprété souverainement leur commune intention quant à cette localisation, de déduire de celle-ci la loi applicable au contrat litigieux." 12

Da mesma forma, na Alemanha, Bélgica, Paises Baixos e em Luxemburgo, a jurisprudência também consagrou as partes a lei de autonomia. Vale referIr que nos paises do BENELUX, a questão vem expressamente colocada no "Tratado Sobre a Lei Uniforme em Metéria de Direito Internacional Privado", firmado em 1969, contrato pode resultar de uma escolha expressa ou implicita das partes (art. 13, 3) ${ }^{13}$.

$\mathrm{Na}$ Itália, o legislador deu um passo adiante quaindo determinou expressamente, nas "Disposiçōes Preliminares do Código Civil de 1942", a autonomia da vontade das partes quanto à lei aplicável ao contrato ${ }^{14}$. 0 mesmo encontramos no Código Civil português ${ }^{15}$.

Continuando com os paises da Civil Law, vêse que o princípio da autonomia da vontade parece que ainda não conseguiu se impor na maioria dos paises da América Latínà, que insistem em conceder a suá própria lei maior competência, com exceção do Peru e do México, depois de 1987.

Dentre os países que compõem o MERCOSUL, no Brasil e Paraguai, a autonomia da vontade ainda não conseguiu se impor, ao passo que na Argentina a jurisprudência tem aceito e 0 principio começa a preponderar ${ }^{16}$; quanto ao Uruguai, a questão resta em debate.

\subsection{O Artigo $9^{\circ}$ da Lei de Introdução ao}

\section{Código Civil Brasileiro}

No que se refere, especificamente, ao ordenamento juridico brasileiro, uma questão impor- tante é saber como se comportará o juiz nacional diante de um contrato internacional onde há cláusula de escolha de lei: ele aceitará que a vontade das partes derrogue a regra contida no art. 9, caput, da Lei de Introdução ao Código Civil brasileiro? ${ }^{17}$

Essa é uma questão extremamente dificil e objeto de debate por parte de nossos doutrinadores, e que não encontra uma resposta precisa na jurisprudência. Então, o melhor para um negociador é procurar, na medida do possivel, compatibilizar o contrato com as leis aplicáveis potencialmente. $O$ que equivale a dizer que não deve ferir os princípios de ordem pública de um ou outro ordenamento juridico em questão, procurando adequar as cláusulas e condiçōes às peculiaridades dos direitos com os quais o contrato se conecta, quer quando se tratè de possivel disputa judicial, quer quando da homologação e eventual execução judicial de um laudo arbitral. Nesta linha de raciocinio, entendemos que 0 art. 9, caput, da Lei de Introdução ao Có. digo Civil brasileiro, como nơma de ordem pública, não pöde ser afastado pela vontade das partes ${ }^{18}$ ). Assim, a regra de prudência que 0 negociador deve observar é procurar realizar o negócio no pais cuja lei pretende que seja aplicada ao contrato, razāo pela qual, é importante a escolha do local da negociação. Todavia, esta não é uma solução definitiva para os possiveis problemas, porque pode aco problemas, rato celebrado num determinado pais, seja executado em outro, ensejando novos problemas quanto à lei aplicável. Diz-nos Luiz Olavo Baptista, com muita propriedade, que "as cláusulas de eleiçăo de lei e foro são, è claro, fórmulas que muitos pensam poder resolver de modo definitivo a questão da lei aplicável". Contudo, afirma o autor, "quem quer que tenha uma certa experiência internacional sabe que elas não geram certezas absolutas. Dai a escolha, por muitos, da cláusula arbitral como meio de evitar os conflitos de lei. Esta não é também uma solução perfeita". Para este autor, "a conclusão é que todos esses recursos devem ser conjugados para que se chegue a um grau maior de certeza jurique se chegue a um grau maior de certeza juri-
dica - que será relativa e não absoluta”. Frente dica - que será relativa e não absoluta". Frente a esta realidade, continua Luiz Olavo: "a verda-
de è a de que não há uma solução universal e que cada contrato é um caso a ser resolvido, à custa de trabalho e competência por parte dos negociadores"19).

\subsection{A Regra da Autonomia da Vontade nos Países da "Common Law"}

Continuando no estudo da lei de autonomia, passamos agora ao sistema da Common Law, portunidade em que constataremos que a lei aplicável ao contrato, a proper law of a contract, é aquela determinada, a título principal, pela escolha das partes, conforme entendimento consubstanciado no caso "Vita Food Products Inc. v. Unus Shipping Co.", de 1939, quando lord Wright sustentou: "it is now well settled that by english law the proper law of the contract is the law which the parties intended to apply"20, principio apoiado pela jurisprudência.

Nos Estados Unidos, durante muitos anos, registrou-se certa confusão e incertezas quanto a determinação da lei aplicável aos contratos, mas finalmente a regra da autonomia das partes acabou por se impor à prática e à doutrina Em 1953, a Suprema Corte, no caso "Lauritzen v. Larsen"21, se pronunciou a favor da regra e. mais tarde, o Uniform Commercial Code (1962) previu também que as partes podem escolher a lei aplicável aos contratos (Seções 1-105).

\subsection{A Autonomia da Vontade na}

\section{Jurisprudência Arbitral e Nas Convenções} Internacionais

A regra da autonomia está também consagrada na prática do comércio internacional e 0 seu reconhecimento fica evidenciado na jurisprudência arbitral, que parece nunca ter posto em dúvida a faculdade das partes de escolherem a lei aplicável ao contrato.

O Tribunal Arbitral de 23 de agosto de 1958 composto para resolver o importante e debatido caso "Saudi Arabia v. Arabian American Oil Company" (caso Aranco), determinou:

"Les principes de droit international privé à consulter pour déterminer laloi applicable sont ceux de l'autonomie de la volonté, en vertú desquels il faut dans une convention ayant un caractère international, appliquer en premier lieu la loi expressément choisie

par les parties, et en second lieu, à defaut 
de choix, la loi présomptivement élue par elles"22.

Em 1977, a questão foi novamente debatida e a regra reafirmada no caso "République Arabe de Libye v. California Asiatic Oil Company et Texaco Overseas Petroleum Company", ocasião em que o único árbito, Dupuy, afirmou:

“Tous les systèmes juridiques, quel qu'ils soient, appliquent le principe de l'autonomie de la volonté aux contrats internationaux. Quant au fond, tous les systèmes juridiques consacrent ce principe, qui apparait dès lors comme universellement reçu, même s'il ne lui est pas toujours donné exactement le même sens ou la même portée" 23

Essa mesma compreensão está nos textos internacionais. A "Convenção Sobre Lei Aplicável às Vendas Internacionais de Objetos Móveis Corpóreos", concluída em Haia (1955), entre vários paises europeus, e que entrou em vigor em 1964, preceitua:

"Art. 2. La venta est régie par la loi interne du pays désigné par les parties contractantes".

No mesmo sentido está a "Convenção Européia sobre Arbitragem Comercial Internacional", concluida em Genebra, em 1961 e que entrou em vigor em 1964:

“Art. 8. Les parties sont libres de déterminer le droit que les arbitres deuront applquer au fond du litige".

Finalmente, a "Convenção de Roma Sobre a Lei Aplicável às Obrigações Contratuais", firma

da em 1980, entre os paises da Comunidade Européia, estabelece:

Art. 3,(1) Il contratto è regolato dalla le gge scelta dalle parti. La scelta dev'essere espressa, o risultare in modo ragionevolmente certo dalle disposizioni del contrattoo dalle circostanze. Le parti possono designare legge applicabile a tutto il contratto, ovvero a una parte sollanto di esso".

Da prática do comércio internacional, e da análise dos textos mais importantes acerca da matéria, decorre que a liberdade de escolha das partes é admitida, normalmente, mesmo que esta resulte de uma manifestação implicita.

Diante disso, que elementos autorizariam o juiz a constatar que as partes fizeram uma verdadeira escolha da lei se esta não estiver expressamente declarada no contrato?
Se poderia dizer que é o conjunto de circunstâncias e elementos do caso concreto, mas esta nos parece uma resposta vaga, razão pela qual reproduziremos algumas situaçōes que, a nosso ver, autorizariam o juiz a fazer esta constatação:

a) quando as partes no contrato anteriormente feito entre elas fizeram uma escolha exos que nos fazem crer que não houve mudança de atias mesmas

b) quando as partes escolheram o forum de um determinado pais como competente para dirimir as possiveis controvérsias; se as leis deste não são incompativeis com as disposicões do contrato, se presume que estas tenham sido também escolhidas pelas partes para reger o contrato

c) quando no contrato as partes tenham feito, em alguma de suas cláusulas, referência ao direito de um determinado pais, por exemplo, ao Código Civil português, pode-se presumir que enham escolhido este direito para reger o contrato;

d) quando estipularam a solução dos litigios através da arbitragem, e determinaram o lugar onde esta deva se realizar, se presume que a lei escolhida seja a deste mesmo lugar ${ }^{24}$.

\section{O MOMENTO EM QUE PODE INTERVIR A \\ LIBERDADE DE ESCOLHA DAS PARTES} QUANTO A LEI APLICÁVEL AO CONTRATO E A QUESTÃO DO "DÉPECAGE"

A questão que decorre quando se debate esta temática é se as partes podem modificar, por novo acordo entre elas, a lei que tinham precedentemente escolhido para reger o contrato.

Mesmo frente às muitas discussões travadas a respeito, a questão parece não ter uma solução aparente. A "Convenção de Roma Sobre Le Aplicável às Obrigações Contratuais" estabelece:

"Art. 3, (2) Le parti possono convenire, in qualsiasi momento, di sottoporre il contratto ad una legge diversa da quella che lo regolava in precedenza, vuoi in funzione di una scelta anteriore secondo il presente articolo, vuoi in funzione di altre disposizioni della presente. convenzione".
Por "qualsiasi momento" se entende a todo momento até a conclusão, e mesmo após, tanto que no mesmo preceito citado (parte final) encontramos:

"qualsiasi modifica relativa alla determinazione della legge applicabile, intervenuta posteriormente alla conclusione del contratto, non inficia la validità formale del contratto $e$ non pregiudica i diritti dei terzi".

Esse entendimento é compartilhado pelos tribunais franceses, alemães, holandeses e ingleses. Todavia, a Corte de Cassação italiana, em um julgamento ocorrido em 1966, caso "As. sael Nissim v. Crespi", declarou que a escolha das partes, quanto a lei aplicável, não é admitida se efetuada posteriormente a estipulação do contrato ${ }^{25}$. Certamente, essa é uma decisão anterior a referida "Convencão de Roma", mas acerca dela continua dividida a doutrina italiana ${ }^{26}$. ca dela continua dividida a doutrina italiana ${ }^{26}$. cão, entendemos que o melhor para um negociador prudente é escolher a lei aplicável quando isso lhe é facultado: durante o periodo de negociação até a conclusão do contrato; escolha esta que deve ser criteriosa e atenta porque uma vez efetuada, convém as partes não alterá-la mais.

Outra questão que se apresenta é se as partes devem escolher um só sistema de direito para reger a totalidade do contrato, ou podem escolher mais de um, isto é, podem realizar um dépecage (divisão do contrato de forma que cada sessão ou segmento seja submetido a sistemas nacionais diversos).

A respeito dessa indagação, existem poucas decisões na prática, mas a tendência é de considerar o dépeçage possivel, desde que o critério adotado pelas partes seja coerente, 0 que equivale a dizer que os diversos direitos que regem os elementos do contrato não podem, quando analisados no seu conjunto, ensejar resultados contraditórios.

Do que se conclui que a opção pelo dépeçage não é fácil, pois harmonizar sistemas de direito com vistas a um determinado resultado não é, via de regra, uma tarefa simples. Em razão disso é que compartilhamos com aqueles autores que entendem que, a principio, o contrato deve ser regido por uma única leí, há não ser que se trate de um grande contrato que se decompõe em outros separáveis e independentes, para os quais as partes podem escolher leis diferentes.
A "Convenção de Roma", não obstante as discussões travadas entre os expertos encarregados da sua redação, tratou o tema do dépeçage em dois momentos, no final do item 1 , do art. 3 : "le parti possono designare la legge applicabile a tutto il contratto, ovvero a una parte soltanto di esso", e mais adiante, no art. 4 ("legge applicabile in mancanza di scelta"), oportunidade em que a "Convenção" possibilita ao julgador, excepcionalmente, atuar com vistas ao dépeçage:

"Art. 4 (1). Nella misura in cui la legge che regola il contratto non sia stata scelta a norma dell'articolo 3 , il contratto è regolato dalla legge del paese col quale presenta il collegamento più stretto. Tuttavia, qualora una parte del contratto sia separabile dal resto e precosto e presenti un collegamento più stretto con un altro paese, a tale parte del contratto potrà applicarsi, in via eccezionale, la legge di quest'altro
paese".

\section{OS LIMITES ESTR ATÉGICOS À ESCOLHA DAS PARTES QUANTO À LEI A PLICÁVEL AO CONTRATO}

A autonomia da vontade, conforme dito anteriormente, sofre limitações que decorrem das noçōes de ordem pública e das regras imperativas (limites legais). Alëm destes, a escolha das partes sofre outras restricones as quais denomima forma, jados, uma vez concluido o contrato.

o primeiro limite estratégico, é o caráter internacional do contrato. Por outras palavras, a aplicação da regra de autonomia está subordinada ao caráter internacional do contrato, não sendo possivel que entre em funcionamento esta regra em se tratando de um contrato puramente interno. A este respeito, encontramos o seguinte fragmento na "Exposição de Motivos da Lei Uniforme BENELUX em Matéria de Direito Internacional Privado":

"dans un contrat international, c'est-à-dire un contrat qui comporte des éléments d'extranéité donnat à plusieurs lois vocation de s'y appliquer, les parties ont la faculté de choisir la loi qui le régira"27.

$\mathrm{Na}$ escolha da lei aplicável ao contrato internacional, as partes devem considerar também. 
como limite estratégico, os sistemas nacionais de direito que estejam em estreita relação com mesmo. Imaginemos, por exemplo, a possibilidade de projetarmos o contrato no espaço, então perceberemos em que ordenamentos juridicos ele irradia efeitos, consoante seus elementos de estraneidade (conexão). A escolha da le aplicável, conseqüentemente, deve recair sobre um destes sistemas nacionais de direito, especialmente sobre aquele com o qual o contrato esteja mais estreitamente vinculado - elemento de conexão relevante.

Não é razoável, portanto, escolher um sistema de direito que não possua qualquer relação com o contrato, sem que se levante, em principio, o problema da fraude à lei.

As partes devem ter presente que a escolha da lei do contrato somente produzirá efeitos se no pais onde ele for aberto a regra de direito internacional privado faculte as partes esta es colha, e se esta corresponder a um legitimo interesse das partes.

Concluindo, para que a cláusula de escolh da lei possa produzir efeitos é preciso respeitar a máxima:

Escollia da Lei (quando facultado Internacional Privado ------------ interesse

do pais onde for aberto das partes

o Contrato)

\section{O CONTRATO SEM LEI E OS LIMITES DA} VONTADE DAS PARTES

Muito difundida e contestada é a tese sustentada por alguns autores ${ }^{28}$ de que o poder de autoregulamentação reconhecido às partes thes consente de disciplinar o contrato segundo às suas necessidades e os interesses do comérci internacional. Desta forma, as partes gozariam da faculdade de submeter o contrato, não a um sistema nacional de direito específico, mas sim aos principios decorrentes da prática comercial internacional, às decisões arbitrais, etc., elaborando um contrato dito sem lei (estatal), ou autoregulamentado.

Os que repudiam essa tese, se baseiam na premissa básica de que no campo da autonomia contratual subsistem as normas imperati- vas e os principios de ordem pública que são inderrogáveis pela vontade das partes.

A faculdade de autoregulamentação dos contraentes, como é sabido, não é ilimitada, não encontra a sua fonte exclusivamente na vontade das partes, mas pressupõe uma lei que a atribua e reconheça.

Então, não é possivel um contrato sem lei, e a este respeito a Corte de Cassação Francesa, no importante caso "Messageries Maritimes" (1950), repudiou a tese do contrato sem lei e decidiu: "tout contrat international est nécessairement rattachë à la loi d'un Etat"29

Um contrato sem lei, ou autoregulamentado, é, sem dúvida, uma prática perigosa na medida em que devemos ter presente que somente a lei pode, em principio, impedir, também nas relaçōes internacionais, que uma das partes, dita economicamente mais forte, explore a mais frágil. Um contrato sem lei facilitaria o desenvolvimento dessas relações contratuais patológicas que se instauram, muitas vezes, no periodo negocial. Em razão disso, o melhor é não recorrermos a tal prática porque somente a lei pode garantir não só o equilibrio da relação contratual, como tambem os interesses de terceiros e outros reconhecidos nos ordenamentos estatais, como as cláusulas econômicas, etc.

\section{O DEBATE ACERCA DA SUBSTITUIÇÃO DO MÉTODO CONFLITUAL DA REGULAMENTAÇÃO DO CONTRATO INTERNACIONAL POR OUTRO MAIS \\ CONSENTÂNEO COM AS PARTICULARIDADES DO COMÉRCIO INTERNACIONAL}

A relação juridica que possui um ou mais elementos de estraneidade é submetida a uma regulamentação especial - jus specialis. Esse direito especial, diferentemente do jus communis, é composto de regras que não regulam diretamente a relação (não fazem juizos lógicos hipotéticos), porém indicam o sistema nacional de direito a ser aplicado ao caso sub judice, consoante 0 elemento de conexão (método indireto de solução)

Disso decorre que o juiz nacional quando se vê diante de um contrato internacional, deve interpretar a regra especial e tirar dela a indicação da regra material (direito substancial) a ser aplicada ao caso concreto, que poderá ser tanto direito nacional, como estrangeiro. A regra que determina a lei aplicável às diferentes relações de direito privado que possuem elementos de estraneidade são tradicionalmente denominada de regras de direito internacional privado ou regras de conflito de leis.

Evidentemente, as regras sobre conflito de leis em matéria de contratos não são necessariamente iguais em todos os sistemas juridicos nacionais, diferenciando-se quanto à determinação do critério (elemento de conexão) que innação do critério (elemento de conexão) que in-
dicará a lei aplicável. Vejamos um exemplo concreto do que se está demonstrando, e para tanto utilizaremos 0 art. 9, caput, da "Lei de Introdução ao Código Civil brasileiro" e 0 art. 25 das "Disposições Preliminares do Código Civil italiano", ambas regras de conflito em matéria obrigacional: art. 9 L.I.C.C. brasileiro:

"Para qualificar e reger as obrigações, aplicar-se-á a lei do país em que se constituirem":

Art. 25 Disp. Prel. C.C. italiano

"Le obbligazioni che nascono da contrat to sono regolate dalla legge nazionale de contraenti, se è comune; altrimenti da quella del luogo nel quale il contratto è stato conchiuso. $\dot{E}$ salva in ogni caso la diversa volontà delle parti."

Quanto a regra de conflito brasileira, se vê que o legislador escolheu, dentre os possiveis elementos de estraneidade que podem porventura vincular-se a uma obrigação, como elemento de conexão o locus regit actum. A solução, portanto para o caso concreto envolvendo contrato inter trato in parnacional apreciado no Brasil, sera extraido do direito substancial do lugar onde contrato foi celebrado - lex loci actum:

1ํ Passo

2ำ Passo

\begin{tabular}{lll}
\hline $\begin{array}{l}\text { Contrato } \\
\text { Internacional } \\
\text { aberto no Brasil }\end{array}$ & $\begin{array}{l}\text { Localização da Norma de } \\
\text { Conflito: art. 9 da LICC }\end{array}$ & $\begin{array}{l}\text { Aplicação do Direito Substancial } \\
\text { do lugar onde o Contrato foi celebrado: } \\
\text { lex loci actum }\end{array}$ \\
\hline
\end{tabular}

Na regra de conflito italiana, contrariamente do que acontece no Brasil, o legislador concede às partes a faculdade de escolha da lei aplicável ao contrato. Porém, se os contraentes não gozarem desta liberdade, o elemento de conexão supletivo que o juiz deve observar é a lex patriae das partes, se comum; caso contrário, a lex loci actum:

\begin{tabular}{lll} 
& $1^{\circ}$ Passo & $2^{\circ}$ Passo \\
\hline $\begin{array}{l}\text { Contrato } \\
\text { Internacional }\end{array}$ & Localização da Norma de & $\begin{array}{l}\text { Aplicação do Direito Substancial } \\
\text { indicado pelas partes, }\end{array}$ \\
aberto na Itália & Conflito: art. 25 das Disp. & $\begin{array}{l}\text { ou supletivamente: a lex patriae ou } \\
\text { a lex loci actum }\end{array}$ \\
\hline
\end{tabular}

\subsection{As Técnicas Alternativas ao Método Conf litual}

Alguns doutrinadores, que denominamos "autonomistas absolutos", ou seja, defensores incondicionais da autonomia contratual das partes, têm sugerido abandonar o método conflitual, analisado acima, porque ele não estaria em condiçōes de regular adequadamente os pro- blemas dos contratos internacionais do comércio. Sustentam, então, que tais contratos devem ser apreciados através de decisões operadas na prática, pois o que ocorre no setor do comércio internacional escapa à perspectiva dos sistemas nacionais das normas de conflito ${ }^{30}$.

A esse respeito, em obra recente, René David nos traz importante contribuição na medida em que aprofunda o debate e faz um balanço da 
situação atual, apresentando um panorama do que ele chama "direito internacional renovado". Sustenta David:

"La soumission du commerce international à des droits nationaux n'est pas en soi une bonne solution; et surtout le commerce international est dominé en maints secteurs par des organisations professionnelles puissantes, dont les entreprises reconnaissent l'autorité... En dehors méme de tout droit corporatif on sait d'autre part que pour une séporatif on sait d'autre part que pour une sé-
rie de raisons de droit des juristes risque de demeurer théoriques: parce qu'il ne parait pas juste ou parce que les intéressés le connaissent mal ou parce que sa mise en oeuvre se heurte à des obstacles d'ordres divers. Ces obstacles sont multipliés dans le cas du commerce international. Le droit national que les juristes peuvent considérer comme applicacle risque dans ces conditions de ne pas recevoir sa pleine application"31.

Das liçōes de David, se conclui que a nacionalização do direito internacional privado cria para o comércio internacional uma situação que apresenta graves inconvenientes, tais como: 1) pluralidade de jurisdiçōes nacionais que se consideram competentes para conhecer de um determinado litigio; 2) diversidade de regras de conflitos de leis aplicáveis por estas jurisdições; 3) diversidade de regras materiais consagradas pelos direitos nacionais que podem aqui e lá ser declaradas aplicaveis; 4) inadaptaçao das regras de direito nacional à especificidade das relaçōes de direito internacional; 5) dificuldade de estabelecer o conteúdo do direito estrangeiro declarado aplicável por uma jurisdição nacional; 6) dificuldades de execução de sentenças estrangeiras $^{32}$.

Tais considerações não podem ser ignoradas por mais consagrado que esteja, no âmbito dos direitos nacionais, o método conflitual como solução dos problemas do contrato internacional. $O$ debate que se abre é extremamente interessante nos estimulando a aprofundar um pouco mais o discurso a ponto de questionarmos a afirponto de exige uma regulamentação especial que consi- dere adequadamente as suas especificidades: qual seria esta nova proposta e qual o seu valor juridico?

Em resposta a essa indagação, procuraremos, ainda que em largos traços, especificar que novas técnicas ou métodos poderiam ser seguidos em substituição ao conflitual.

\subsubsection{As Leis de Aplicação Imediata}

Comecemos por um método que na verdade retrocede no que se refere às teses autonomistas surgidas no âmbito do comércio internacional, mas que também merece seu espaço no debate que ora propomos. Referimo-nos à técnica que defende a não consideração do elemento de estraneidade contido no caso que está sendo analisado, e a aplicação imediata das regras substanciais do direito interno que lhe são relativas: leis de aplicação imediata. Esse procedimento se baseia fundamentalmente no principio do "exclusivismo da ordem juridica", e na mentalidade de que o direito do foro é o mais adequado, não só porque seus tribunais o cothecem methor como porque ele é o mais adequado que se pode utilizar ${ }^{33}$

\subsubsection{O Direito Internacional Privado} Material

O segundo método alternativo ao conflitual è a utilização, para a disciplina dos contratos internacionais, do intitulado direito internacional privado material, segundo o qual o legislador pode adotar uma solução diversa, isto é, criar um verdadeiro e próprio sistema de direito substancial para as relaçōes juridicas que apresentam elementos de estraneidade.

Cassoni, que considera esse método a via a ser seguida, recorda que esta técnica existia no direito romano quando, ao lado do jus civile, foi criado o jus gentium, cuja fonte estava na jurisdicio do praetor peregrinus, e se encontra no Código Civil tchecoslovaco, de 4 de dezembro de 1963, no qual o legislador disciplinou compleinternacional ${ }^{34}$.
0 direito internacional privado material pode encontrar suas fontes nos tratados internacionais e na função normativa do juiz ${ }^{35}$.

\subsection{3. o Contrato Sem Lei ou}

\section{Autoregulamentado}

Uma terceira possibilidade é a elaboração de um contrato sem lei, ou autoregulamentado (visto anteriormente), no qual as partes submetem 0 contrato às suas próprias necessidades e à realidade do comércio internacional.

\subsubsection{A Opção Pela Nova "Lex Mercatoria"}

Finalmente, a técnica que se apresenta, como substituição ao método conflitual tradicional, é a possibilidade de escolher para o contrato, como ei aplicável, a nova lex mercatoria.

É sabido que o comércio internacional está submetido às novas necessidades e às novas práticas, que vão surgindo sem que nos apercebamos sob a forma de cláusulas standard, de contratos-tipo, de condições gerais, de usos que vão se reiterando, consagrando e difundindo, até se transformarem em principios e institutos novos que resultam do influxo das relações internacionais.

Os negócios internacionais são para os juristas um verdadeiro desafio, pois eles se vêem obrigados a adaptar as necessidades de seus clientes à sistemas juridicos e legislações muitas vezes divergentes, até mesmo quanto a principios básicos.

O comércio internacional, por conseguinte, exige negócios mais rápidos e seguros, impostos menores, lucros maiores, e desta realidade inexorável surge um conjunto de normas não estatais, um direito transnacional do comércio, ao qual se convencionou chamar nova lex mercatoria: usos e costumes nos quais a prática internacional se conforma.

Sobre a nova lex mercatoria muito já se escreveu desde que em 1960 começaram a surgir os primeiros textos projetando a idéia de um direito internacional especifico para as relaçoes econômicas ${ }^{36}$. A partir de então, se multiplicaram as discussōes doutrinárias a respeito do chamado direito internacional econômico, da nova lex mercatoria do direito transnacional. porém as interrogações fundamentais, observa
Philippe Kahn, subsistem acerca da natureza deste direito e das instituições nascidas da prática $^{37}$

Não intencionamos aqui abrir esta discussão, todavia algumas reflexões nos permitimos apresentar para que possamos impostar a maéria em modo critico.

A teoria da nova lex mercatoria se baseia fundamentalmente nos contratos internacionais, na riqueza de figuras contratuais nascidas da prádos das cláusulas elaboradas pelas partes, como também nas operações do comércio internacional que se realizam fora de referências precisas aos direitos nacionais. Conseqüentemente, os práticos do comércio internacional constituiram uma comunidade (societas mercatorum) que elabora as suas proprias regras. Tambem as senproferidas em controvérsias proverias envolvendo contratos internacionais, têm papel de destaque na teoria da nova lex mercatoria. Finalmente, poder-se-ia citar os regulamentos stabelecidos pelas organizações profissionais.

Por conseguinte, como método alternativo ao conflitual, a nova lex mercatoria oferece como contes: as condiçoes gerais de compra e venda internacional, os contratos-tipo, os usos codificados e, como jurisdição, a arbitragem internacional.

\subsection{Crítica às Técnicas Alternativas e}

Observações Acerca de Uma Possível Solução aos Problemas da Aplicação do Método Conflitual aos Contratos Internacionais do Comércio

No que se refere ao método que prevê a aplicação imediata das regras substanciais do direito do foro, "leis de aplicação imediata”, sem considerar os elementos de estraneidade, se pode dizer que parte de um fundamento equivocado e que representaria, a nosso ver, um retrocesso relativamente às conquistas já obtidas pelo direito internacional privado, na medida em que se baseia no "exclusivismo da ordem juridica", num momento juridico-politico em que a unificacão de certos segmentos dos direitos nacionais se torna mais e mais freqüente. Há que se questionar também o critério de justiça e eqüidade dos possiveis julgamentos proferidos com base neste sistema, já que o juiz estaria adstrito 
a aplicar sempre o corpo de normas de seu território mesmo quando, consoante os elementos de estraneidade, deveria aplicar direito substancial estrangeiro. Talvez, por estas razões, hoje praticamente nenhum país adota este método titulo principal

No que diz respeito ao "direito internacional privado material", nos parece que se foi possive e útil aos romanos erguer um jus gentium ao lado do jus civile, poderia ser também hoje uma possibilidade. Entretanto, exigiria uma nova reestruturação juridica e novamente encontrariamos paises que 0 adotariam e outros não. Conseqüentemente, as dificuldades no que concerne as divergências de tratamento quanto disciplina dos contratos internacionais persistiria. São válidos os argumentos que sustentam como fonte do direito internacional privado material a função normativa do juiz, que agindo com plena autonomia atua como se fosse um legislador. Isso já ocorre na França, onde o juiz ainda que não autorizado expressamente pelo Código Civil, opera criando uma jurisprudênci que poderia ser considerada como uma disciplina material autônoma dos contratos internacionais.

Acerca do "contrato sem lei", resta pouco acrescentar, uma vez que a vontade dos contraentes não é absoluta, nem toma seu ponto de apoio em si mesma, encontrando seu sustenta culo na lei, que the deu forma e sanciona; conforme bem demonstra Vincent Heuz ao criticar em seu livro, o dogma da autonomia da vonta$\mathrm{de}^{38}$.

No que se refere a nova lex mercatoria, muitas questões emergem, para as quais ainda não temos uma resposta precisa. A primeira delas determinar se a nova lex mercatoria constitu uma ordem juridica nas mesmas condiçōes que as ordens juridicas estatais, ou a ordem inter nacional. Conseqüentemente, se a lex mercatoria constitui uma ordem juridica, esta coexistiria com as ordens estatais e com a ordem inter nacional? Como se daria esta coexistência, com base na coordenação ou na exclusão? E, final mente, como se comportam as ordens estatais também a internacional frente a nova lex mer catoria?

Esses são pontos inevitáveis que foram entusiasticamente enfrentados por Paul Lagard tusiasticamente enfrentados por Paul Lagard e
Ph, Kahn em estudos recentes ${ }^{39}$. Berthold Gold- man, a propósito, no seu primeiro artigo sobre o tema, escrito em 1964, defendeu que "le caractere ments constitutifs de la lex mercatoria", e mais tarde, em 1979, completou que "la lex mercatoria remplit bien la fonction d'un ensemble de règles de droit ${ }^{\prime 40}$

Com muita objetividade Ugo Draetta coloca: "la lex mercatoria appare quindi in questa ottica come um vero e proprio sistema normativo che fonda la sua giuridicità sulla effettività, sia nel senso di concreta attitudine a regolare fattispecie contrattuali complesse relativamente alle quali gli ordinamenti interni si rivelano inadequati, sia nel senso di capacità di imporsi come giuridicamente vincolante per gli operatori economici, in virtu della opinio necessitatis che essi nutrono nei suoi confronti" 41 .

Sem levantar as controvérsias acerca da naureza da nova lex mercatoria, porque teriamos indubitavelmente, que enfrentar as teses oposicionistas, o que exigiria entrar num campo de investigação que por si só ensejaria um trabatho especifico, cumpre-nos reconhecer que como sistema ordinário de normas, a nova lex mercatoria já encontra o seu reconhecimento em regras especificas, como acontece no Código de Processo Civil francês, que sofreu modificações em 1981 (Dec. no 81-500), cujo art. 1497 preceitua:

"l'arbitre tranche le litige conformément aux règles de droit que les parties ont choisies: à defaut d'un tel choix, conformément à celles qu'il estime approprièes. Il tient compte dans tous les cas des usages de commerce.

Da mesma forma, a nova lex mercatoria é reconhecida nas sentenças arbitrais internacionais.

Não obstante a irrefutável constatação de que a nova lex mercatoria é a lei mais adequada a regular o contrato internacional (a racionalidade das teses dos seus idealizadores isso revela), devemos precisar que até 0 presente momento não é possivel uma referência direta à nova lex mercatoria como disciplina dos contratos internacionais, porque sozinha ela não tem condicoos de regulá-lo. Todavia, estã em condiçōes de concorrer com um ou vários sistemas nacionais de direito.
É preciso reconhecer, por um lado, que a nova lex mercatoria ainda se encontra em estado difuso, mesmo que tenhamos as publicaçōes das sentenças arbitrais da Câmara de Comércio Internacional de Paris, nas quais não se exaurem as suas fontes ${ }^{42}$. Por outro lado, precisamos ter presente que os contratos internacionais ainda encontram sua legitimação nos ordenamentos internos, e, para uma melhor interpretação e mais adequado julgamento, contam com a boa vontade jue com base nos "principios gerais de direito" e nos "costumes", podem reconhecer os usos do comércio internacional como fontes de direito, realidade corrente na França. Os contratos internacionais contam também com a perspicácia dos legisladores que podem elaborar normas adequadas para a mapodem elaborar normas adequadas para a maaconteceu na Tchecoslováquia: e até mesmo com a ratificação dos tratados internacionais de caráter comercial que são ipso facto incorporados ao direito interno.

Sem dúvida, faz-se imprescindivel uma disciplina especifica dos contratos internacionais Todas as téc tuicão do método conflitual são suscetiveis de criticas. Somente um estudo mais profundo nos permitirá avaliar até que ponto se pode reconhecer a autonomia negocial das partes; se é aquela reconhecida segundo os vários ordenamentos juridicos internos, ou é mais ampla inserindo-se nos principios da nova lex mercato$\mathrm{ria}^{43}$.

Enquanto resta em aberto o debate, a solução é, inicialmente, reconsiderar as normas de conflito (método tradicional) em matéria de contratos, as quais podem se diferenciar uma das outras em razão da pluralidade de ordens juridicas. Então, devemos compará-las entre si, procurando identificar as semelhanças e diversidades de solução com referência a prática, com des de solução com referencia a pratica, com

vistas à adoção de regras de conflito uniforme ${ }^{44}$.
$\hat{E}$ preciso, portanto, conceder as partes a fa-

É preciso, portanto, conceder as partes a faculdade de escolha da lei aplicável ao contrato. Nesse sentido, desempenham papel importante as "Conferências Especializadas de Direito Internacional Privado", da Academia de Direito Internacional de Haia, bem como os estudos do Internacional de Haia, bem como os estudos do UNIDROIT - Instituto Internação do Direito Privado.
Entendemos que a harmonização das regras de conflito em matéria contratual, resolveria, em principio, os inconvenientes que decorrem da diversidade dessas regras nos vários ordenamentos juridicos. Nesse sentido, os esforços dos paises que compõem a União Européia revelam que tal medida é possivel

0 mesmo poder-se-ia intentar nos países que integram 0 MERCOSUL ${ }^{45}$, 0 que não impediria num segundo momento, a unificacão da maté ria num plano internacional mais vasto, onde 0 alicerce seria um "direito internacional renovado", obra de juristas e não juristas, administradores e comerciantes preparados para compreender os problemas transnacionais fora de suas próprias tradiçōes nacionais. A elaboração de um direito internacional melhor estaria vinculado, portanto, ao desenvolvimento dos estudos de direito comparado indispensáveis à formação de juristas, juizes e árbitros imbuidos de um espirito internacional ${ }^{46}$.

\section{NOTAS DE REFERÊNCIA}

1 No Brasil, dois extraordinários trabalhos abordam esta matéria: o primeiro deles de Irineu Strenger "Da automonia da vontade em direito internaciona privado". São Paulo: RT, 1968; e o segundo de Jacob Dolinger, "Evoluçāo da ordem pública no direito internacional privado". Rio de Janeiro, 1979.

2 "Lautonomia privata". Milano: Giuffrè, 1959, p. 5. Ainda sobre este argumento: Francisco dos Santos Amaral Neto, "A automomina privada como principio cundamental da ordem juridica - perspectivas es-

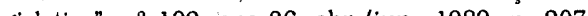
gisla.

A este respeito interessantissimo é o trabalho de $P$ Lagarde: "Recherches sur l'ordre e oublic en droit international privé". Paris: L.D.G.J., 1959, p. 175 e 5 "Co.

5 "Contratos internacionais do comércio", São Paulo: RT, 1986, p. 98

6 "La règlementation française des contrats internationaux - étude critique des méthodes". Paris: More et Corduant, 1990, p. 85

7 "Contratos..," p. 99.

Segundo Barthèlemy Mercadal, citado por Strenge "Contratos...", p. 97-8.

9 Acerca das origens historicas da regra de autonomia, destaca-se o trabalho de Edoardo Vitta, "Diritto internazionale privato". Torino: U.T.E.T, 197275 , v.3, p. $218-33$.

Vide: Curti Gialdino, "La volonté des parties en droit international privê", in "Recueil des Cours", v. 137 
1972, II, p. 850 e ss; Mario Giuliano, "La loi applicable aux contrats: problemes choisis", in "Recue des Cours", v. 158, 1977, V, p. 195-270; Vicent Heuzé, "La règlementation..., p. 110 e ss.; e "The International Encyclopedia of Comparative Law" 1975 , v. 3, cap. 4

11 "Journal du Droit International" (Clunet), 1912, p. 1156 .

12 "Journal du Droit International" (Clunet), 1980, p. 650, com notas de Ph. Kahn.

13 "Bulletin BENELUX", 1969. 1942, art. 25: "Le obbligazioni che nascono dal contratto sono regolate dalla legge nazionale dei connel quale il contratto è stato conchiuso. É salva in ogni caso la diversa volontà delle parti".

15 As disposiçōes de Motivos do Decreto-Lei no $n^{0} 46$ As disposiçōes de Motivos do Decreto-Lei no $\mathrm{n}^{0} 446 /$
85 , de 25 de outubro de 1985 , regulador das "clá 85 , de 25 de outubro de 1985 , regulador das "clau-
sulas contratuais gerais", e que alterou o Código sulas contratuais gerais", e que alterou o Código
Civil português, dispōe que "constitui a liberdade Civil portuguès, dispoe que "constitui a liberdade contratual um dos principios basicos do direito priçōes preliminares integras, ao fim das quais as partes, tendo ponderado os respectivos interesses e os diversos meios de os prosseguir, assumem, com discernimento e liberdade, determinadas estipulaçōes. A essa luz, uma boa, medida de direito dos contratos possui natureza supletiva: as normas legais apenas se aplicam quando os intervenientes, no exerccio legitimo da sua autonomia privada, as não tenham afastado...

16 Acerca do direito argentino, Antonio Boggiano, "De recho internacional privado", $2^{\mathrm{a}}$ ed. Buenos Aires: Depalma, 1983, v. 2, p. 460 e ss.

17 Art. 9, caput, da Lei de Introdução ao Código Civil brasileiro: "Para qualificar e reger as obrigaçōes

aplicar-se-á a lei do país em que se constituirem".
18 É importante registrar que Roberto Ago, acerca desta ematica, defendeu: "in diritto internazionale privave perchè le norme di diritto internaze e dispositinon sono norme di diritto sostanziale, ma nomina di collegamento il cui compito è unicamente di determinare la legse sostanziale entro i limite della gualle potrà sorgere effetivamente la questione delle norme obbligatorie e dispositive", in "Studi di diritto internazionale privato". Padova: C.E.D.A.M.. 1932 p. 135. Mais recentemente, Giuseppe Cassoni, referindo a Curti Gialdino, afima: "certo il principio dell'autonomia dei contraenti (e cioè autonomia delle parti nella determinazione della legge applicabile al loro contratto) include anche il diritto cogente ma si tratta appunto del diritto cogente proprio dell'ordinamento designato come competente dalla norma di collegamento e non gia di quello che appartiene all ordinamento di base, e cioè il complesso delle norme imperative sulla formazione del contratto e gli effetti del medesimo", in "Lo jus gentium come metodo per la disciplina del contratto internazionale e dell'arbitrato commerciale internazionale", "Rivista di Diritto Comunitario e Degli Scambi Internazionale", 1986, ano XXV, p. 289-310. Com base nessas teorias, e que se desenvolveram algumas teses que tentaram salvar, no Brasil, bem como em outros paises, a autonomia das partes minação da lei aplicável ao contrato.

19 "Advocacia nas negociaçōes internacionais", in "Revista de Direito Público", no 78, abr./jun., 1986, p. 195.

AC.277 (P.C.) 289, e acerca da doutrina: Albert Venn dres: Stenvens \& Sons; 1973, p. 720 e ss.

21 Vide Mario Giuliano, "La loi applicable...", p. 203

21 "ide Maro Gillano, "La lol applicable..., p. 203 230-49 citacão p. 244. Tal regra já fora evocada. em 1929, pela Corte Permanente de Justica Internacional, no caso dos empréstimos brasileiros, conforme se vê in C.P.J.I, série A, ns. 20 e 21 , p. 122 e ss.

23 "Rivista di Diritto Internazionale" (Roma), 1978, p. 514-71, citação p. 518

24 A respeito do comportamento do juiz, vide Mario Giuliano, "La loi applicable...", p. 217-18.

25 "Rivista di Diritto Internazionale Privato e Processuale", Padova, C.E.D.A.M, 1967, p. 126-38.

26 Vide Treves, "Sulla volonta delle parti e sul momento del suo sorgere", in "Rivista di Diritto Internazionale Privato e Processuale", Padova, C.E.D.A.M. 1967, p. 315-35.

27 Bulletim BENELUX (1969), p. 50

Dentre os quais M. Wolf, "Some observations on the autonomy of the contracting parties in the conflict of law", in "The Grotius Society Transactionns" 1950, v. 35, p. 152 e ss.; Level, "Le contrat dit sans lo1", in "Travaux du Comite Français de Droit Inter-

29 "Revue Critique de Droit International Privé", 1950. p. 609 e ss.

30 Vide Cerbone e Luzzatto, "I contratti del commercio internazionale", in "Trattato di diritto privato", v. 1, tomo 3, p. 117 e ss.; Giuseppe Cassoni, "Lo jus gentium...", p. 290-310; Bruns et Motulsky, "Tendances et perspectives de l'arbitrage international", in
"Revue International de Droit Compare", 1957, p. 717 e ss.: Vincent Heuzé, "la règlementation..." 95 e ss.

31 "Le droit du commerce international - rèflexions d'un comparatista sur le droit international privê". Paris: Ėconomica, 1987, p. 131.

32 Obra citada nota 31, p. 11

33 Vide Phocion Francescakis, "Quelques précisions sur es lois d'application immediate et leurs rapports avec les regles des confits de lois", in "Revues Critique de Droit International Prive", 1966, p. 1 e ss.

34 "Lo Jus gentium...", p. 292.

55 Acerca deste metodo, ainda: Edoardo Vitta, "Cours général de droit international privé", in "Recueil des Cours", 1979, I, p. 126 e ss.: Pierre Lalive, "Ten-
dances et méthodes en droit international privé", in "Recueil des Cours", 1977, II, p. 90 e ss.

36 Philippe Kahn, "La vente commerciale internationa le". Paris: Sirey, 1961; Berthold Goldman, "Le drolt des sociétés internationales", in "Journal du Drot International", 1963, p. 320 e ss. e, do mesmo autor, "Frontières du droit et lex mercatoria, in "Archives de la Philosophie du Droit", tomo IX, 1964 p. 177 e ss.; Prosper Weil, "Le droit international économique, mythe ou realité", in "Aspects du Droit International Economique: Actes du Vé. Colloque de la Société Française Pour le Droit International, Paris:Pedone, 1972, p. I e ss.; M. Bonell, "Le rego, 182 e ss.

37 Ph. Kahn, "Le contrat économique international stabilité et evolution". Bruxelles-Paris: BruylantPedone, 1975, p. 172

38 Vincent Heuzé, "La règlementation française...", 64 e ss.

P. $\mathrm{Ph}$. Kahn, "Droit international économique, droit du dévéloppement, lex mercatoria: concept unique ou pluralisme des ordres juridiques?, ambos in "Le droit des relations économiques internationales - études offertes à Berthold Goldman". Paris: LITEC, 1982, p. 125-50 e p. 97-107, respectivamente.

40 "Frontières du droit et lex mercatoria, p. 189; e "La lex mercatoria dans les contrats et larbitrage internationaux: rèalites et perspectives", in "Journal du Droit International" (Clunet), 1979, p. 475 e ss., respectivamente

41 "Il diritto dei contratti internazionale". Padova: CEDAM, 1984, p. 14

2 Neste sentido é importante a colocação de Ugo Draetta:"anzitutto occorre tener presente che la lex mercatoria si sta sviluppando in determinate aree solamente, allinenti alla disciplina der rapport contrattulit a le parli co la capacita delle persone, vizi del volere, e molte altre, che dovranno continuare ad essere regolate da una legge statale. Ma pur nell'ambito commerciale, in alcuni casi è il c.d. dlritto internazionale uniforme che si fa strada, quale, immesso negli ordinamenti interni attraverso le varie procedure di adattamento, potrà essere a volte inderogabile per le parti... In secondo luogo, sulla base dei noti principi di dintto incrnazionale privato, le norme di applicazto le ens a cox no non applicarsi al contratto sottoposto alla lex mercatoria", in "Il diritto dei contratti...", p. 21.

43 Vide G. Nori. "Normative applicabile ed autonomia nei contratti internazionali: spunti problematici", in "Rivista di Diritto Comunitario e Degli Scambi Internazionali", 1988, p. 569 e ss.; e Dino Rinoldi, "La problematica della codificazione degli usi del commercio internazionale", in "Rivista di Diritto Comunitario e Degli Scambi Internazionali", 1986, p. 311 e ss.

4 Neste sentido, Mario Giuliano, "La loi applicable...", introdução e conclusão.

No processo de unificaçáo das normas de conflito em materia de contratos internacionais entre os paises do MERCOSUL, devemos partir dos Trabalhos das "Conferencias Especializadas Interamericanas de Direito Internacional Privado - CIDIPs, realizadas pelo Comitê Juridico Interamericano da Organização dos Estados Americanos, especialmente a CIDIP IV, muitas já ratificadas pela Argentina, Uruguai e Paraguai, e para as quais o Brasil permanece silencioso. A respello da CIDIP iv, se recomenda Antonio Boggano, "Contrato Buenos Aires. Depalna, 1900. Wale conito represenben na. na.
R. David
p. 142. 